\title{
Peeling of key lime (Citrus aurantifolia) fruit aided with vacuum infusion, different levels of pectinase concentration and soaking time
}

\begin{abstract}
The application of enzymatic peeling technology aided with vacuum infusion has been studied extensively in this study to ease the peeling process of key lime (Citrus aurantifolia) fruit. Through response surface methodology, the optimum parameters such as vacuum pressure $(450-600 \mathrm{mmHg})$, pectinase concentration $(0.5-1.0 \%, \mathrm{v} / \mathrm{v})$, duration of soaking time (15-45 min) and their efects on physicochemical properties of key lime fruit have been determined. The optimal conditions determined in this study were $600 \mathrm{mmHg}$ of vacuum pressure, $0.93 \% \mathrm{v} / \mathrm{v}$ of pectinase concentration and $45 \mathrm{~min}$ of soaking time. The physicochemical properties analysed such as colour, $\mathrm{pH}$, titratable acidity, total soluble solids, moisture content, and ascorbic acid content show no signifcant ( $p>0.05$ ) efect of enzymatic-peeling on quality parameters of key lime fruit products. The intensity of puree colour was signifcantly $(\mathrm{p} \leq 0.05)$ improved by the vacuum-aided enzymatic treatment. Overall, vacuum-aided enzymatic treatment is an improved peeling method compared to the conventional method as it simplifes the process, reduces processing time and retains quality parameters of the key lime fruit products.
\end{abstract}

Keyword: Enzymatic peeling; Key lime fruit; Response surface methodology; Soaking time; Vacuum infusion 